\title{
Una asociación incluyente
}

\author{
An inclusive association \\ Uma associação inclusiva
}

\author{
Angélica María Pérez Cano*
}

https://doi.org/10.35454/rncm.v4n4.354

Desde hace varios años, la Asociación Colombiana de Nutrición Clínica (ACNC) se ha empeñado en llevar a la región programas de educación que permitan fortalecer la práctica en nutrición clínica hasta que, por motivos de la pandemia por la enfermedad por coronavirus de 2019 (COVID-19), se suspendieron estas actividades. Luego de la apertura de actividades grupales y de establecer las condiciones para generar confianza en los profesionales de la salud, se reestablecen las actividades presenciales. El pasado 23 de octubre, en la ciudad de Pereira se llevó a cabo una reunión con la participación de 80 asistentes, en la que a través de una agenda académica se enfatizaron los siguientes aspectos: las necesidades de la región, la gestión administrativa de los departamentos de nutrición y los equipos de soporte metabólico y nutricional, la atención nutricional en pacientes críticos, las heridas crónicas, los avances en inmunonutrición y en pacientes oncológicos, entre otros.

Adicionalmente, la junta directiva de la ACNC está convencida de la importancia de una renovación de la imagen corporativa acompañada de una filosofía organizacional que se basa en una nueva misión y visión, descritas a continuación:

\section{MISIÓN}

Es una organización sin ánimo de lucro, conformada por profesionales de la salud que trabajan interdisci-

*Correspondencia: Angélica María Pérez Cano.

presidencia@nutriclinicacolombia.org plinariamente, promoviendo esfuerzos colaborativos estratégicos entre los miembros y el sector salud, el Gobierno, la industria y otras organizaciones que trabajan en pro del derecho al cuidado nutricional y la lucha contra la malnutrición. Su misión se centra, con un enfoque basado en los derechos humanos y la ética, en contribuir a mejorar la calidad de vida de los pacientes y de la población en general a través de la educación alimentaria y nutricional, y la investigación en nutrición en los diferentes ámbitos.

\section{VISIÓN}

Para 2026 la ACNC continuará siendo un referente nacional e internacional para las buenas prácticas en nutrición clínica, a través de la mejor evidencia científica disponible, por medio de la educación, investigación, gestión y uso de las tecnologías de la información y las comunicaciones (TIC).

Los objetivos estratégicos renovados que permiten desarrollar nuestro objetivo social son:

- Educación: contribuir a que los profesionales de la salud que trabajan interdisciplinariamente en el área tengan un mejor conocimiento de la nutrición clínica, por medio de eventos educativos con el uso de las TIC.

- Investigación: promover la generación de conocimiento a través de programas de investigación en diferentes campos y ofrecer entornos de divulgación y discusión del mismo, respetando los principios éticos. 
- Regulación: articular con los diferentes entes gubernamentales y no gubernamentales la adopción de medidas que permitan, desde el enfoque de los derechos humanos, que todos los pacientes tengan acceso al cuidado nutricional y que las instituciones implementen procesos de cuidado nutricional y una adecuada aplicación de la nutrición clínica en Colombia.

- Satisfacción: identificar las necesidades de los asociados para mejorar su experiencia en la ACNC y promover, a su vez, el incremento de nuevos asociados.

- Representación: aumentar la visibilidad y alianza de la ACNC con las otras sociedades científicas, el Ministerio de Salud y los colectivos de pacientes, para ofrecer su opinión y consejo experto en las materias que constituyen su fin.

- Difusión: la ACNC, a través de su órgano de difusión, la Revista de Nutrición Clínica y Metabolismo, asume la responsabilidad de la transmisión de conocimiento a nivel nacional e internacional, alineada con el cumplimento de la misión y la visión de la ACNC.

Desde el mes de septiembre estamos buscando en todo el país líderes en nutrición clínica que quieran participar en los diferentes comités de especialización para desarrollar en la ACNC diversas actividades académicas y generación de conocimiento en cada temática. Los seguimos invitando a ser parte activa de la ACNC y acompañar este sueño conjunto de mejorar siempre la práctica clínica en nuestro país. Los comités son:
- Lactancia y nutrición pediátrica.

- Terapia médica especializada (gestión, administración y condiciones seguras en la nutrición artificial).

- Cirugía y optimización de desenlaces.

- Cuidado crítico.

- Ética médica, humanismo e investigación.

- Polimorbilidad y sarcopenia.

- Nutrición deportiva y estilos de vida saludables.

Como se puede analizar, la actual junta directiva le apuesta a la inclusión, al trabajo en equipo y a la reactivación presencial de actividades. El próximo año nos encontraremos nuevamente en nuestro congreso nacional, que se realizará en el mes de mayo de manera presencial en el Centro de Convenciones Ágora, en la ciudad de Bogotá.

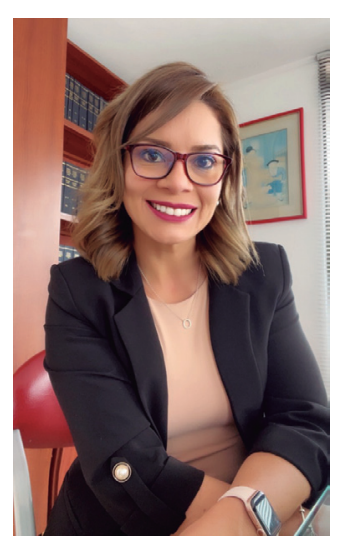

Angélica María Pérez Cano, ND, Esp, MSc(c) Coordinadora nacional, Colombia nutritionDay Jefe del departamento de nutrición, Hospital Universitario Infantil de San José Presidente de la ACNC 